\title{
CCAAT-enhancer binding protein delta (C/EBP $\delta)$ attenuates tubular injury and tubulointerstitial fibrogenesis during chronic obstructive nephropathy
}

\author{
JanWillem Duitman ${ }^{1}$, Keren S Borensztajn², Willem PC Pulskens ${ }^{3}$, Jaklien C Leemans ${ }^{4}$, Sandrine Florquin ${ }^{4,5}$ and \\ C Arnold Spek ${ }^{1}$
}

CCAAT-enhancer-binding protein delta (C/EBP $\delta$ ) is a transcription factor mainly known for its role in inflammation and apoptosis/proliferation. Considering that these are key processes in renal fibrosis, we hypothesized that $\mathrm{C} / \mathrm{EBP} \delta$ would potentiate renal fibrosis. In line with this hypothesis, C/EBP $\delta$ has recently been suggested to regulate the fibrotic response during glomerulonephritis. Here we determined the importance of C/EBP $\delta$ in the development of renal tubulointerstitial fibrosis by subjecting 8- to 12-week-old C/EBP $\delta$-deficient mice and age- and sex-matched wild-type controls to the unilateral ureteral obstruction model. Mice were killed at 1, 3, or 7 days post surgery, and renal tissues were obtained for RNA, protein, and immunohistochemical analysis. We show that C/EBP $\delta$ deficiency resulted in a more profound fibrotic response as evident from enhanced tubular injury, collagen deposition in the interstitial area, and higher expression of transforming growth factor- $\beta$. Moreover, we show that the increase in renal fibrosis in C/EBP $\delta$-deficient mice does not depend on an altered proliferation/apoptosis balance or on a differential inflammatory response in the obstructed kidney. In conclusion, our study provides direct evidence that C/EBP $\delta$ is a novel mediator of renal fibrosis. Modulating C/EBP $\delta$ expression could consequently be a potential antifibrotic strategy in patients with chronic kidney disease.

Laboratory Investigation (2014) 94, 89-97; doi:10.1038/labinvest.2013.127; published online 18 November 2013

KEYWORDS: CEBP; C/EBP $\delta$; chronic kidney disease; interstitial fibrosis; transcriptional regulation; vascular barrier

Tissue fibrosis is, in general, a hallmark of chronically failing organs and is a leading cause of morbidity and mortality. ${ }^{1}$ Renal fibrosis is not an exception and is indeed a major risk factor for the progression to end-stage renal disease and consequently a strong predictor for renal disease outcome. ${ }^{2}$ Interestingly, in most renal diseases, irrespective of the originating compartment, interstitial fibrosis is the principal common pathway leading to end-stage renal disease (ESRD). ${ }^{3}$ Although not completely understood, renal fibrosis is probably initiated by a robust inflammatory response, which occurs upon disruption of normal tubular integrity ${ }^{4,5}$ and the loss of the renal capillary network. ${ }^{6,7}$ Subsequently, the accumulation of interstitial leukocytes and myofibroblasts leads to excessive extracellular matrix (ECM) production eventually leading to tubular atrophy and loss of renal function. ${ }^{8-10}$
The different stages of obstructive nephropathy leading to tubulointerstitial fibrosis are frequently studied using the wellestablished murine unilateral ureteral obstruction (UUO) model. ${ }^{4}$ In this particular model, tubulointerstitial disease is associated with progressive tubular cell loss and atrophy caused by an imbalance in proliferation and apoptosis. ${ }^{9,11}$ Moreover, a strong increase in the accumulation of macrophages in the tubulointerstitial compartment is observed. ${ }^{9,12}$ Next to these 'early' events, transforming growth factor (TGF) $\beta$ expression is induced, which is highly relevant, as TGF- $\beta$ is an important mediator of fibrosis by mediating (myo)fibroblast proliferation and accumulation, epithelial to mesenchymal transition, and ECM production. . $^{13,14}$

CCAAT-enhancer-binding protein $(\mathrm{C} / \mathrm{EBP}) \delta$ is a member of the C/EBP family of transcription factors. ${ }^{15}$ Originally

\footnotetext{
${ }^{1}$ Center for Experimental and Molecular Medicine (CEMM), Academic Medical Center, University of Amsterdam, Amsterdam, The Netherlands; ${ }^{2}$ Unité INSERM 700, Physiopathologie et Epidémiologie de I'Insuffisance Respiratoire, Faculté de Médecine Xavier Bichat, Paris, France; ${ }^{3}$ Department of Physiology, Radboud University Nijmegen Medical Centre, Nijmegen, The Netherlands; ${ }^{4}$ Department of Pathology; Academic Medical Center, University of Amsterdam, Amsterdam, The Netherlands and ${ }^{5}$ Department of Pathology, Radboud University Nijmegen Medical Centre, Nijmegen, The Netherlands

Correspondence: JW Duitman, MSc, Center for Experimental and Molecular Medicine, Academic Medical Center, Meibergdreef 9, Amsterdam, NL 1105 AZ, The Netherlands. E-mail: J.W.Duitman@amc.uva.nl
}

Received 16 July 2013; revised 2 October 2013; accepted 8 October 2013 
identified as a transcription factor that is rapidly upregulated during the acute phase response, shortly after its discovery, C/ $\operatorname{EBP} \delta$ was already implicated in cell proliferation. Nowadays $\mathrm{C} / \mathrm{EBP} \delta$ is believed to act as a tumor suppressor because of its ability to decrease expression of cell cycle proteins cyclin D1 and cyclin E, while increasing the expression of p27. ${ }^{16-18}$ Moreover, $\mathrm{C} / \mathrm{EBP} \delta$ regulates pro-apoptotic gene expression during mammary gland involution ${ }^{19,20}$ and inhibits the growth of human cell lines from different tumor types in vitro. ${ }^{16,21,22}$ In line, increased mammary epithelial cell proliferation and ductal hyperplasia is one of the main features observed in $\mathrm{C} / \mathrm{EBP} \delta$-deficient mice. ${ }^{23}$ Together, these data suggest that $\mathrm{C} / \mathrm{EBP} \delta$ has an important role in the balance between cell proliferation and apoptosis.

Recently, $\mathrm{C} / \mathrm{EBP} \delta$ expression in macrophages emerges as a key process in pathophysiology. Indeed, we recently showed that macrophage recruitment during Klebsiella-induced pulmonary infection is markedly reduced in $\mathrm{C} / \mathrm{EBP} \delta$-deficient mice, and the reduced number of macrophages correlated with reduced Klebsiella-induced mortality in $\mathrm{C} / \mathrm{EBP} \delta$-deficient mice. ${ }^{24}$ Moreover, $\mathrm{C} / \mathrm{EBP} \delta$ modulates the expression of CCL20, interleukin (IL)-23, CXCL1, and TNFAIP6 in macrophages, and these $\mathrm{C} / \mathrm{EBP} \delta$ targets subsequently potentiate the pathogenesis of rheumatoid arthritis, ${ }^{25}$ whereas macrophage $\mathrm{C} / \mathrm{EBP} \delta$ also induces phagocytosis of apoptotic neuronal cells. ${ }^{26}$ Finally, a recent paper shows that C/EBP $\delta$ directly drives LPS-induced tumor necrosis factor- $\alpha$, IL-6, and macrophage inflammatory protein-2 in pulmonary macrophages, ${ }^{27}$ which may be due to $\mathrm{C} / \mathrm{EBP} \delta$-dependent tolllike receptor-4 expression. ${ }^{28}$

Interestingly, $\mathrm{C} / \mathrm{EBP} \delta$ also modifies renal inflammation, as C/EBP $\delta$ deficiency protected against Habu snake venom-induced glomerulonephritis. In this particular model, $\mathrm{C} / \mathrm{EBP} \delta$ deficient mice showed reduced smooth muscle $\alpha$-actin $(\alpha \mathrm{SMA})$ expression in the glomeruli and diminished deterioration of renal function as compared with wild-type mice. $^{29}$ Whether $\mathrm{C} / \mathrm{EBP} \delta$-dependent $\alpha \mathrm{SMA}$ expression is causally linked to Habu-venom-induced renal dysfunction, however, remains to be established.

Overall, C/EBP $\delta$ might thus be involved in some of the key processes leading to tubulointerstitial fibrosis, and therefore we hypothesized that $\mathrm{C} / \mathrm{EBP} \delta$ would aggravate renal fibrosis. We challenged this hypothesis by evaluating renal fibrosis in wild-type and $\mathrm{C} / \mathrm{EBP} \delta$-deficient mice subjected to the unilateral ureter obstruction (UUO) model. Surprisingly, we show that $\mathrm{C} / \mathrm{EBP} \delta$ limits UUO-induced renal fibrosis, and this protective effect of $\mathrm{C} / \mathrm{EBP} \delta$ seems independent of the proliferation/apoptosis balance or of the infiltration of macrophages.

\section{MATERIALS AND METHODS \\ Mice}

Specific pathogen-free 8- to 12-week-old female C57BL/6 mice were purchased from Charles River and C/EBP $\delta$-deficient mice (on a C57BL/6 background; generated as described previously $y^{30}$ ) were bred in the animal facility of the Academic Medical Center with free access to food and water. Mice used for experiments were age and sex matched. The Animal Care and Use Committee of the University of Amsterdam approved all animal experiments.

\section{Experimental Model}

Mice were subjected to the well-established model of renal progressive injury (ie, unilateral ureteral obstruction; UUO) as described previously. ${ }^{31}$ Before surgery, all mice received analgesia (subcutaneous injection of $50 \mu \mathrm{g} / \mathrm{kg}$ buprenorphine (Temgesic; Shering-Plough)). During surgery, the right ureter was ligated with 6-0 silk surgical suture through a small abdominal incision under $2.0 \%$ isoflurane-induced anesthesia. Subsequently, the abdomen was closed. Mice were killed 1,3 , or 7 days after surgery, and kidneys were collected for further analysis. Contralateral non-obstructed kidneys served as control as described before. ${ }^{31,32}$

\section{Histopathological Scoring}

To score renal injury, formalin-fixed paraffin embedded PASD-stained slides were analyzed by a pathologist (S.F.) in a blinded manner with respect to the following parameters: tubular dilatation, epithelial simplification, and interstitial expansion. Lesions were graded on a scale from 0 to $4: 0=$ normal; $1=$ mild, involvement of less than $25 \%$ of the cortex; $2=$ moderate, involvement of 25 to $50 \%$ of the cortex; $3=$ severe, involvement of 50 to $75 \%$ of the cortex; $4=$ extensive damage involving more than $75 \%$ of the cortex. Edema as evident from increased interstitial space was also graded in a blinded manner according to the following: $0=$ normal; $1=$ mild, $2=$ moderate, and $3=$ severe amount of edema. The final score of each slide was the average of 10 randomly chosen, non-overlapping fields in the cortex of the obstructed kidney at a $\times 400$ magnification.

\section{Immunohistochemistry}

$\mathrm{C} / \mathrm{EBP} \delta$ protein expression was determined using a rabbitanti C/EBP $\delta$ antibody (\#2318; Cell Signaling Technologies) as described before. ${ }^{33}$ Collagen staining was performed using a rabbit-anti-collagen type I (GTX41286; GeneTex) antibody as described before. ${ }^{34}$ Proliferative and apoptotic cells were detected using rabbit anti-Ki67 (\#RM-9106; Lab Vision) and anticleaved caspase-3 (\#9661S; Cell Signaling Technologies) antibodies essentially as described before. ${ }^{35}$ In short, after deparaffinization and endogenous peroxidase inhibition, slides were boiled in citrate buffer (pH6.0) for $10 \mathrm{~min}$, blocked with normal goat serum for $30 \mathrm{~min}$, and incubated overnight with the primary antibody $(1: 1000$ for $\mathrm{C} / \mathrm{EBP} \delta$, 1:500 for Ki67, 1:200 for cleaved caspase-3 and 1:400 for collagen type I) at $4{ }^{\circ} \mathrm{C}$. Subsequently, slides were incubated with Powervision PolyHRP-anti-rabbit IgG (DPVR-55HRP; Immunologic) for $30 \mathrm{~min}$ at room temperature and stained using DAB (BS04-999; Immunologic). 


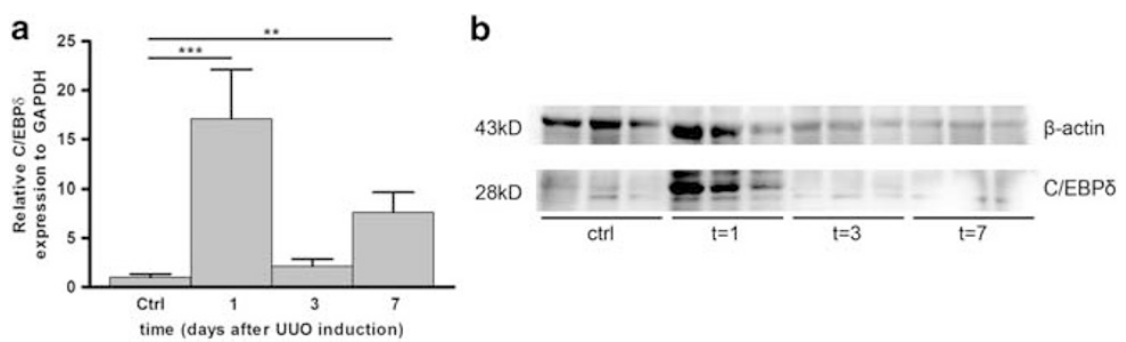

Figure $1 \mathrm{C} / \mathrm{EBP} \delta$ protein expression is increased during UUO. mRNA (a) and protein (b) levels of C/EBP $\delta$ in wild-type kidney before and after induction of UUO. (c-f) Immunohistochemical staining of C/EBP $\delta$ protein expression in wild-type kidney before (c) and 1 (d), 3 (e), or 7 (f) days after induction of UUO. ( $\times 20$ magnification; insets $\times 40$ magnification). Arrow $(\rightarrow)$ : tubular epithelial cells; arrowhead $(\mathbf{\Lambda})$ : pericytes/smooth muscle cells; open arrowhead $(<)$ : monocytes. Double staining of C/EBP $\delta$ (brown) with NCC (g; blue) or SGLT2 (h; blue) in wild-type kidney 1 day after induction of UUO $\left(40 \times\right.$ magnification). Data are means \pm s.e.m. ${ }^{* *} P<0.01,{ }^{* * *} P<0.001$.

Co-localization of tubular segmentation markers with C/EBP $\delta$ was assessed using rabbit-anti-SGLT2 (proximal tubules) and rabbit-anti-NCC (distal tubules) antibodies. After performing the $\mathrm{C} / \mathrm{EBP} \delta$ staining as described above, slides were boiled in citrate buffer (pH6.0) for $10 \mathrm{~min}$ and incubated overnight with the primary antibody (1:400 for SGLT2 and 1:800 for NCC) at $4{ }^{\circ} \mathrm{C}$. Subsequently, slides were incubated with Powervision PolyAP-anti-rabbit IgG (DPVR55AP; Immunologic) for $30 \mathrm{~min}$ at room temperature and stained using the Vector Blue Alkaline Phosphatase Substrate Kit (SK-5300; Vector Labs).

\section{Detection of Macrophages}

Macrophage staining was carried out using a rat-anti-F4/80 antibody (MCA497GA; AbD Serotec) as described before. ${ }^{24}$ In short, slides were deparaffinized and endogenous peroxidase was inhibited by $0.3 \% \mathrm{H}_{2} \mathrm{O}_{2}$ in methanol for $10 \mathrm{~min}$. Slides were boiled in citrate buffer (pH6.0) for $20 \mathrm{~min}$, blocked with Ultra V block for $10 \mathrm{~min}$, and incubated overnight with the primary antibody $(1: 500)$ at $4{ }^{\circ} \mathrm{C}$. Sections were then incubated with a Rabbit (FAB2)-anti-rat IgG (\#6130-01; ITK Diagnostics) 1:3000 in 20\% Normal Mouse Serum/PBS for $30 \mathrm{~min}$. Subsequently, slides were incubated with Powervision PolyHRP-anti-rabbit IgG (DPVM-55HRP; Immunologic) for $30 \mathrm{~min}$ at room temperature and stained using DAB (BS04-999; Immunologic).

\section{Cytokine Detection}

Active TGF- $\beta$ and hepatocyte growth factor (HGF) levels were measured using ELISA (R\&D Systems) according to the manufacturer's recommendations.

\section{RNA Isolation and RT-PCR}

For gene expression analysis, mRNA was isolated from kidney homogenates using Tripure isolation reagent (\#11667165001; Roche Diagnostics) according to the manufacturer's recommendations. All mRNA samples were quantified by spectrophotometry and stored at $-80^{\circ} \mathrm{C}$ until further analysis. mRNA was DNAase treated (\#M6101; Promega, the Netherlands) after which cDNA was prepared. Gene expression analysis was performed using a Roche lightcycler with SYBR green PCR master mix (\#04707516001; Roche) using the QuantiTect mouse c/ebp $\delta$ primer assay kit (\#QT00312809; Qiagen Benelux).

\section{Western Blot}

After electrophoresis of the samples on a $12.5 \%$ SDS-PAGE gel, proteins were transferred onto Immobilon-P membranes (Millipore). The blots were blocked for $1 \mathrm{~h}$ at room temperature in 5\% Bovine Serum Albumin (BSA) in TBS + 0.1\% Tween-20 (TBS-T). Rabbit-anti-C/EBP $\delta$ (\#2318; Cell Signaling Technologies) and mouse-anti- $\beta$-actin (sc-81178; Santa Cruz Biotechnology) were diluted 1:1000 in TBS-T supplemented with $5 \%(\mathrm{C} / \mathrm{EBP} \delta)$ or $1 \%(\beta$-actin) BSA. Membranes were incubated overnight at $4{ }^{\circ} \mathrm{C}$, washed in TBS-T, and incubated with a HRP-linked secondary antibody (1:1000 in TBS-T). After $1 \mathrm{~h}$ of incubation at room temperature, blots were washed in TBS-T and imaging was performed using Lumi-Light (12015200001; Roche) and an ImageQuant LAS 4000 biomolecular imager for chemiluminescence (GE Healthcare).

\section{Statistics}

Differences between groups were analyzed using a $t$-test if data in all groups were normally distributed or with a Mann-Whitney $U$-test when the data were not normally distributed. Analyses were performed using GraphPad Prism version 5.0.

\section{RESULTS \\ Unilateral Ureteral Obstruction Induces C/EBP $\delta$ Expression}

In order to determine whether $\mathrm{C} / \mathrm{EBP} \delta$ might have a role during UUO-induced fibrosis, we first assessed C/EBP $\delta$ expression during UUO. To this end, C/EBP $\delta$ mRNA levels in control and obstructed kidneys of wild-type mice were analyzed. As shown in Figures 1a and c, EBP $\delta$ mRNA levels rapidly increase with peak levels 1 day after the induction of UUO. Next, we assessed C/EBP $\delta$ protein levels by western blot again showing increased $\mathrm{C} / \mathrm{EBP} \delta$ expression 1 day after UUO induction (Figure 1b). To identify the cell types expressing $\mathrm{C} / \mathrm{EBP} \delta$, kidney sections of control and obstructed wild-type 

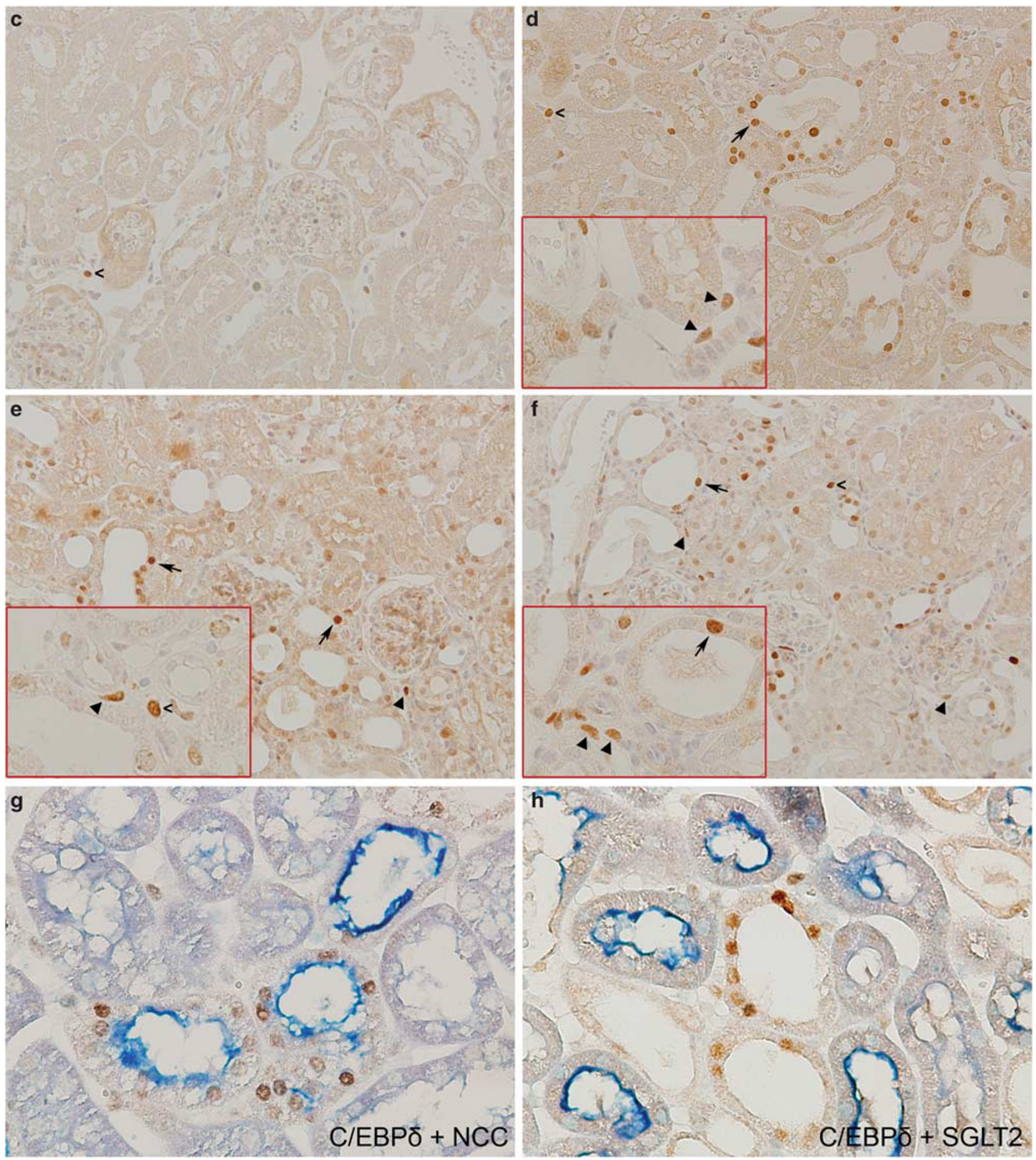

Figure 1 (Continued)

mice were subjected to immunohistochemical analysis using a specific $\mathrm{C} / \mathrm{EBP} \delta$ antibody. As shown in Figures $1 \mathrm{c}-\mathrm{f}$, in control kidney (Figure 1c), some cells, probably monocytes, express $\mathrm{C} / \mathrm{EBP} \delta$. Upon UUO (Figures $1 \mathrm{~d}-\mathrm{f}$ ), tubular epithelial cells and pericytes/smooth muscle cells also stained positive for $\mathrm{C} / \mathrm{EBP} \delta$. Finally, we performed co-localization AQexperiments for C/EBP $\delta$, NCC (distal tubular marker) and SGLT2 (proximal tubular marker). As shown in Figures $1 \mathrm{~g}$, h and c, EBP $\delta$ co-localizes with NCC but not with SGLT2, showing $\mathrm{C} / \mathrm{EBP} \delta$ is mainly expressed in distal tubules. 

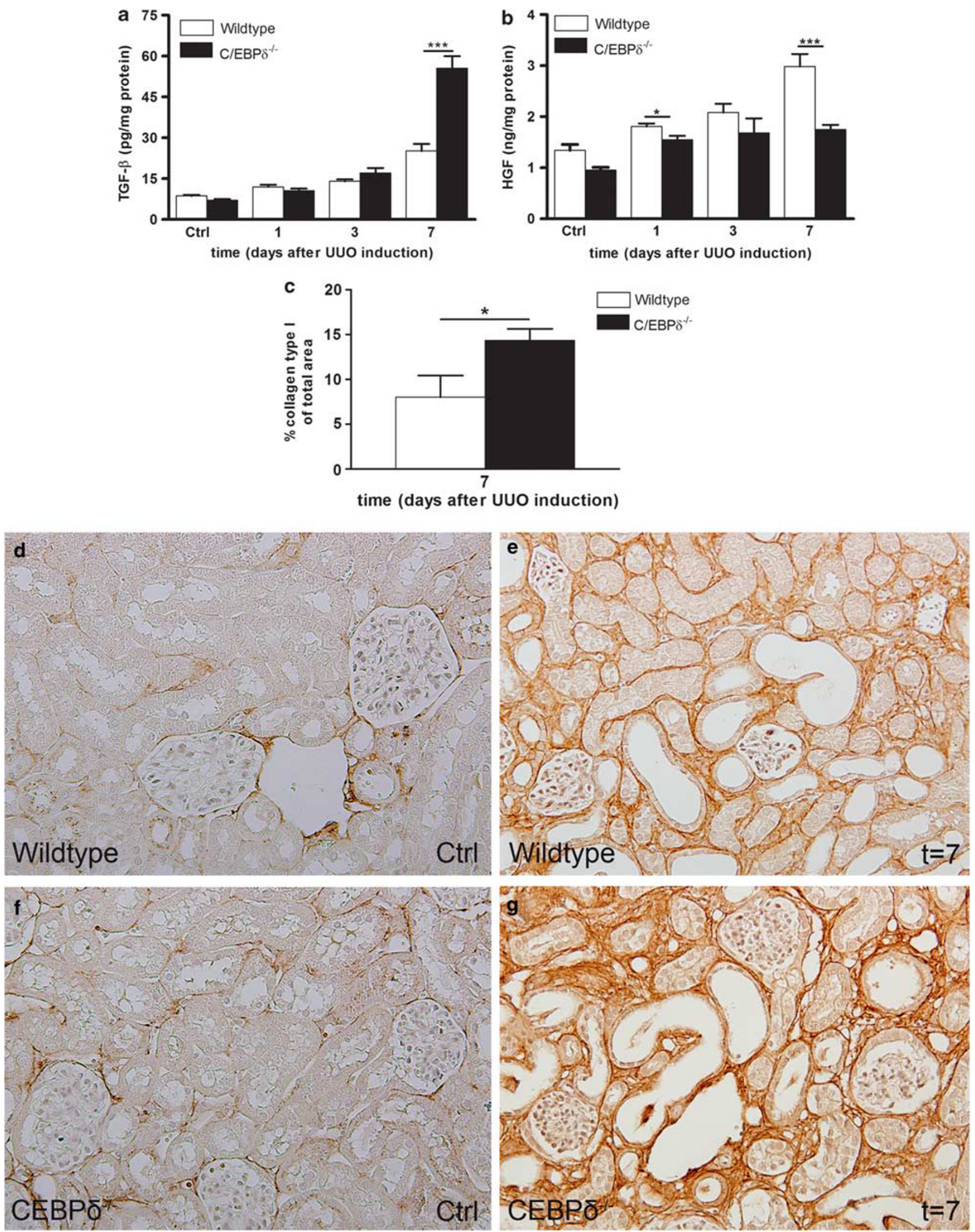

Figure $2 \mathrm{C} / \mathrm{EBP} \delta$ attenuates tubulointerstitial fibrogenesis. (a) Active TGF- $\beta$ and (b) HGF levels in kidney homogenates of wild-type and C/EBP $\delta$-deficient mice during UUO. Data are means \pm s.e.m. $(n=6-8)$. (c) Quantification of collagen type I protein levels in obstructed kidneys of wild-type and C/EBP $\delta$-deficient mice 7 days after induction of UUO. Data are means \pm s.e.m. $(n=8)$. $(\mathbf{d}-\mathbf{g})$ Immunohistochemical staining of collagen type I protein expression in control ( $\mathbf{d}$ and $\mathbf{f}$ ) and 7 days obstructed ( $\mathbf{f}$ and $\mathbf{h}$ ) kidneys of wild-type ( $\mathbf{d}$ and $\mathbf{e})$ or C/EBP $\delta$-deficient (f and $\mathbf{g})$ mice. ( $\times 20$ magnification). ${ }^{*} P<0.05,{ }^{* * *} P<0.001$. 

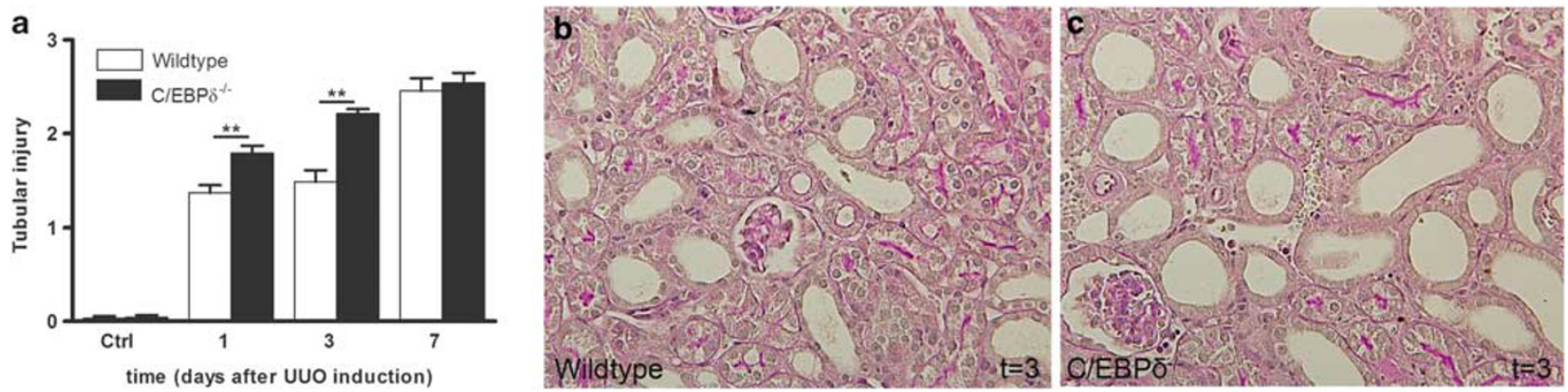

Figure 3 C/EBP $\delta$ deficiency aggravates tubular injury. (a) Quantification of tubular injury in wild-type and C/EBP $\delta$-deficient obstructed kidneys. Data are means \pm s.e.m. $(n=6-8)$. ${ }^{* *} P<0.01$. (b, c) PAS-D staining of obstructed kidneys of wild-type and C/EBP $\delta$-deficient mice 3 days after induction of UUO ( $\times 20$ magnification).
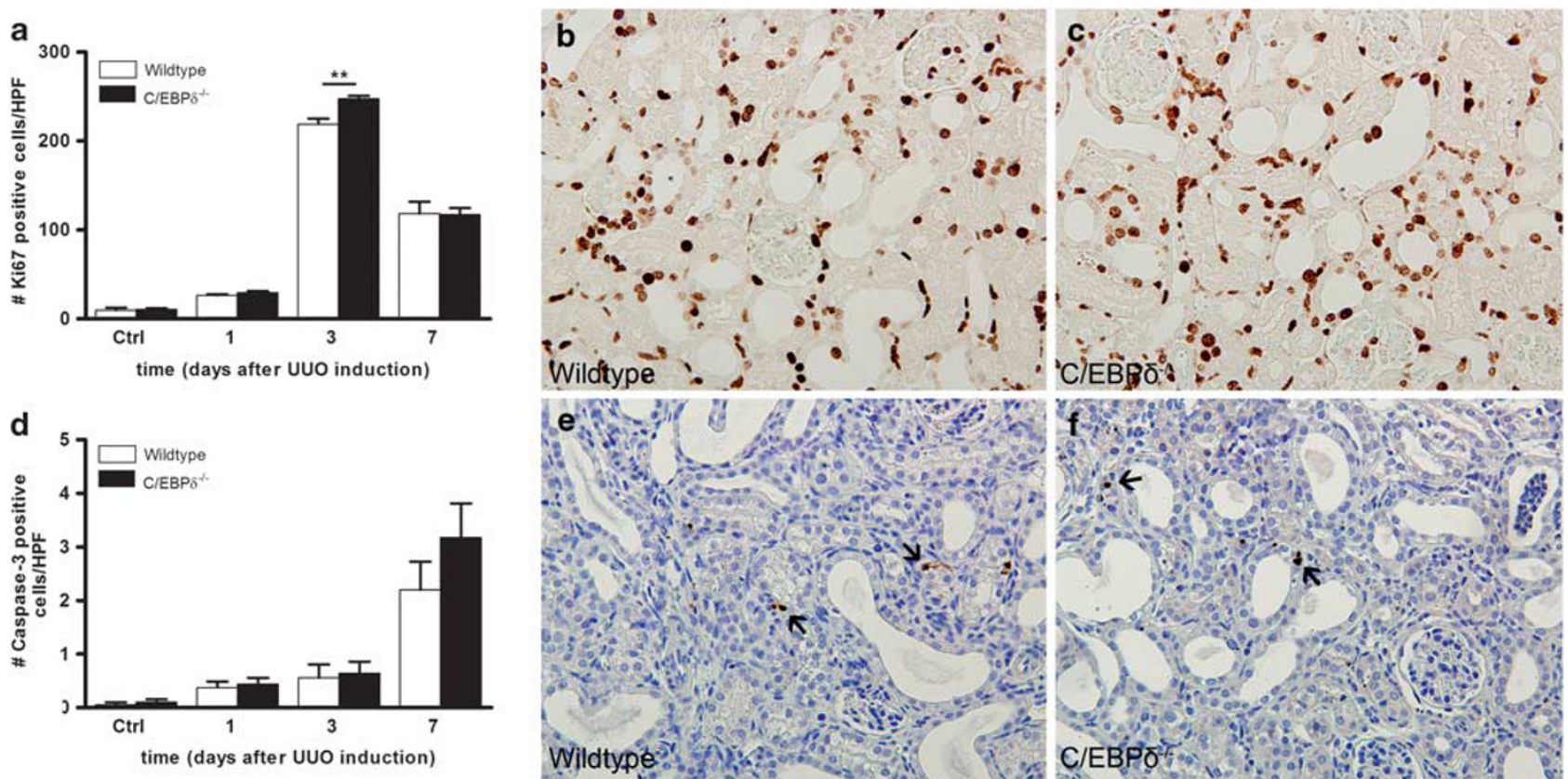

Figure $4 \mathrm{C} / \mathrm{EBP} \delta$ deficiency slightly influences the balance between proliferation and apoptosis. (a) Quantification of Ki67 expression in wild-type and C/EBP $\delta$-deficient obstructed kidneys. (b, c) Ki67 immunohistochemical staining of obstructed kidneys of wild-type (b) and C/EBP $\delta$-deficient (c) mice 3 days after induction of UUO ( $\times 20$ magnification). (d) Quantification of cleaved-caspase-3 protein expression in wild-type and C/EBP $\delta$-deficient obstructed kidneys. (e, f) Cleaved-caspase-3 immunohistochemical staining of obstructed kidneys of wild-type (e) and C/EBP $\delta$-deficient (f) mice 7 days after induction of UUO ( $\times 20$ magnification). Arrows indicate cleaved-caspase-3-positive cells. Data are means \pm s.e.m. $(n=6-8)$. ${ }^{* *} P<0.01$.

\section{C/EBP $\delta$ Limits UUO-Induced Renal Fibrosis}

One of the most important mediators in the genesis of renal interstitial fibrosis is TGF- $\beta,{ }^{13,36}$ whereas HGF levels counteract the action of TGF- $\beta .^{36}$ Consequently, we next determined whether C/EBP $\delta$ modifies TGF- $\beta$ and/or HGF production by analyzing both proteins in kidney homogenates of wild-type and $\mathrm{C} / \mathrm{EBP} \delta$-deficient mice subjected to the UUO model. As shown in Figure 2, active TGF- $\beta$ (Figure 2a) and HGF (Figure 2b) levels increased over time during UUO in wild-type animals. Interestingly, active TGF- $\beta$ levels were two times higher in $\mathrm{C} / \mathrm{EBP} \delta$-deficient mice as compared with wild-type mice 7 days after induction of
UUO, whereas HGF levels were significantly attenuated in C/ $\operatorname{EBP} \delta$-deficient mice at day 7 .

One of the major hallmarks of renal fibrosis is the accumulation of ECM proteins in the interstitium, ${ }^{9,14,36}$ and consequently we analyzed collagen type I deposition in the obstructed kidneys by immunohistochemistry. As shown in Figures $2 \mathrm{c}-\mathrm{g}$, collagen type I was highly present in obstructed kidneys 7 days after induction of UUO. Interestingly, collagen type I levels were significantly higher in $\mathrm{C} / \mathrm{EBP} \delta$-deficient animals compared with wild-type mice (Figures 2c-g). Together, these results suggest that $\mathrm{C} / \mathrm{EBP} \delta$ limits renal fibrosis during obstructive nephropathy. 

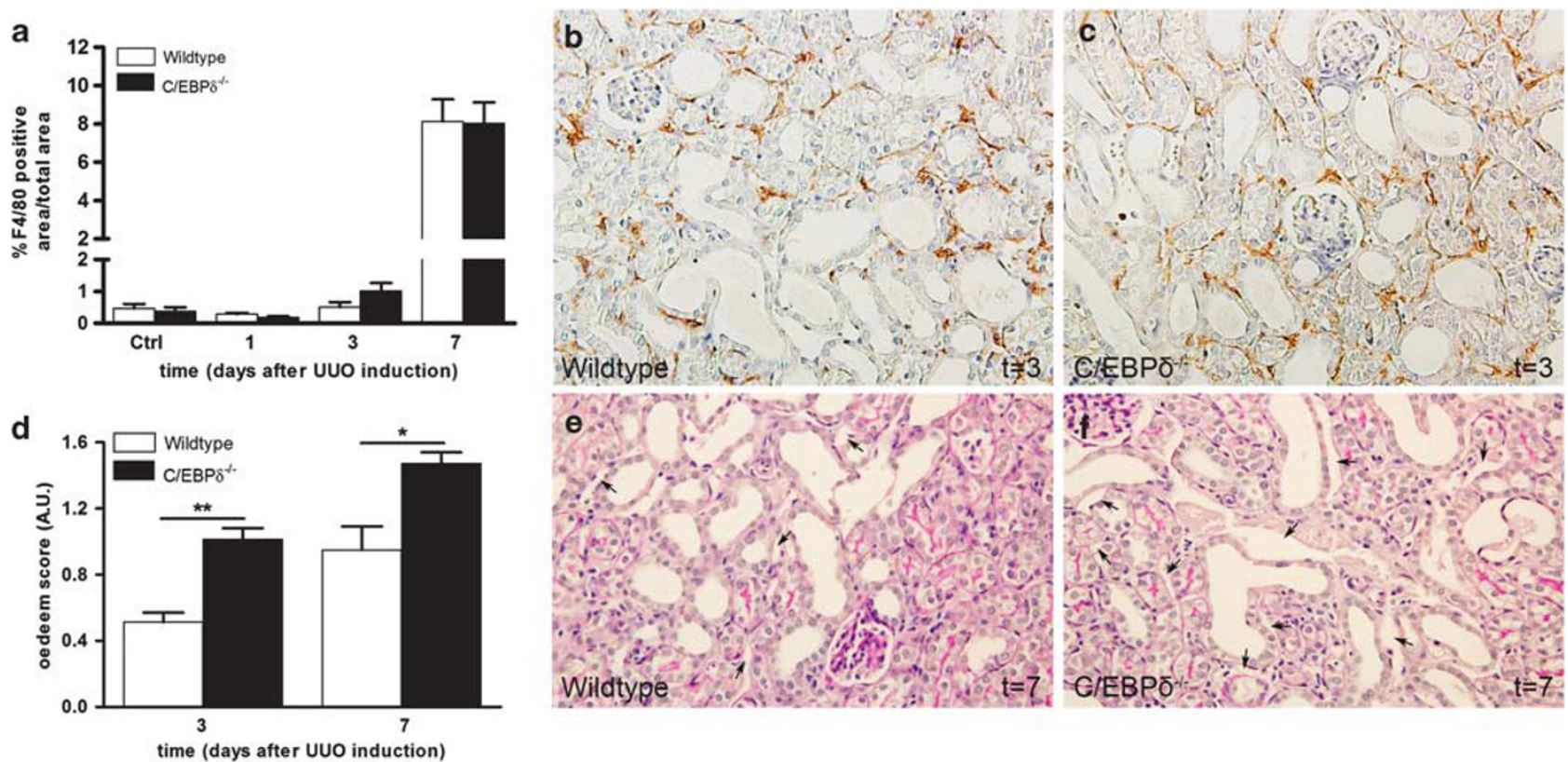

Figure $5 \mathrm{C} / \mathrm{EBP} \delta$ does not influence macrophage accumulation in obstructed kidneys, but limitis edema formation during UUO. (a) Quantification of F4/80 protein expression in wild-type and C/EBP $\delta$-deficient obstructed kidneys. (b, c) F4/80 immunohistochemical staining of obstructed kidneys of wild-type (b) and C/EBP $\delta$-deficient (c) mice 7 days after induction of UUO ( $\times 20$ magnification). Data are means \pm s.e.m. $(n=6-8)$. (d) Quantification of edema in wild-type and C/EBP $\delta$-deficient obstructed kidneys. (e and $\mathbf{f}$ ) Representative pictures of PAS-D-stained wild-type and C/EBP $\delta$-deficient kidney slides 7 days after the induction of UUO. Arrows $(\rightarrow)$ indicate edema. Data are means \pm s.e.m.; $n=6-8 .{ }^{*} P<0.05,{ }^{* *} P<0.01$.

\section{C/EBP $\delta$ Protects Against Tubular Injury}

Tubular injury directly drives the formation of interstitial fibrosis. ${ }^{37}$ Consequently, we assessed the contribution of C/ $\operatorname{EBP} \delta$ to the development of tubular injury. As shown in Figure 3, UUO led to tubular injury in both wild-type and C/ $\operatorname{EBP} \delta$-deficient animals. Interestingly, UUO-induced tubular damage was increased in $\mathrm{C} / \mathrm{EBP} \delta$-deficient mice 1 and 3 days post obstruction as compared with wild-type mice. This difference in tubular damage was not observed anymore at day 7 post obstruction, but at this time point end-stage renal disease was reached and tubular injury scores were close to maximum in both genotype groups. $\mathrm{C} / \mathrm{EBP} \delta$ thus limits UUO-induced tubular injury.

\section{The Role of C/EBP $\delta$ in the Balance Between Proliferation and Apoptosis}

To determine whether the increased tubular injury in $\mathrm{C} / \mathrm{EBP} \delta$-deficient obstructed kidneys was related to a distortion in the balance between proliferation and apoptosis, we assessed the number of proliferating and apoptotic cells immunohistochemically. As shown in Figures $4 \mathrm{a}-\mathrm{c}$, the number of Ki67-positive proliferating cells increased after the induction of UUO with peak levels at day 3. The number of proliferating cells was significantly increased in $\mathrm{C} / \mathrm{EBP} \delta$ deficient mice as compared with wild-type mice at day 3 after the induction of UUO. However, the difference is rather small $(11.5 \%)$. As shown in Figures $4 \mathrm{~d}-\mathrm{f}$, the number of cleaved caspase-3-positive apoptotic cells also increased over time with peak levels at day 7 after the induction of UUO. The increased numbers of apoptotic cells did, however, not significantly differ between the two genotypes. Overall, C/EBP $\delta$ seems to slightly affect proliferation without affecting apoptosis during UUO, and the minimal alteration in the proliferation/apoptosis balance does not seem to explain the protective effect of $\mathrm{C} / \mathrm{EBP} \delta$ on fibrosis.

\section{C/EBP $\delta$ does not Affect the Inflammatory Response upon UUO}

Next to proliferation/apoptosis, an early event in chronic obstructed nephropathy is a progressive inflammatory response as reflected by the recruitment of macrophages. ${ }^{4}$ In order to assess whether differential macrophage influx correlated with the observed difference in fibrosis in wildtype and $\mathrm{C} / \mathrm{EBP} \delta$-deficient mice, we assessed $\mathrm{F} 4 / 80$-positive macrophages in the obstructed kidneys. As shown in Figures $5 a-c$, macrophage numbers increased drastically between 3 and 7 days after the induction of UUO. However, the number of macrophages did not differ between wild-type and $\mathrm{C} / \mathrm{EBP} \delta$-deficient obstructed kidneys, suggesting that macrophage infiltration does not contribute to the protective effect of $\mathrm{C} / \mathrm{EBP} \delta$ on fibrosis.

\section{C/EBP $\delta$ Increases Vascular Leakage}

Renal microvasculature injury constitutes an important mechanism in renal fibrosis, and disruption of the endothelial integrity may potentiate fibrosis after obstruction of the ureter. Consequently, we assessed the extent of edema in both wild type and $\mathrm{C} / \mathrm{EBP} \delta$ deficient at day 3 and 7 after the 
induction of UUO. Interestingly, as shown in Figures $5 \mathrm{~d}-\mathrm{f}$, the amount of edema was significantly increased in obstructed kidneys from $\mathrm{C} / \mathrm{EBP} \delta$-deficient mice as compared with wild-type mice, showing that $\mathrm{C} / \mathrm{EBP} \delta$ limits vascular leakage during UUO.

\section{DISCUSSION}

Independent of the primary cause, tubulointerstitial fibrosis is the final common pathway of many chronic kidney diseases that finally leads to ESRD. It is thus important to get better insight into the mechanisms underlying renal fibrosis in order to design new therapeutic strategies for limiting progressive renal disease. Interestingly, $\mathrm{C} / \mathrm{EBP} \delta$ recently emerged as a transcription factor involved in both proliferation and inflammation. Considering the importance of proliferation and inflammation in tubulointerstitial fibrosis, we hypothesized that $\mathrm{C} / \mathrm{EBP} \delta$ would drive fibrosis and consequently that $\mathrm{C} / \mathrm{EBP} \delta$ deficiency would limit renal fibrosis. Unexpectedly, however, we show that $\mathrm{C} / \mathrm{EBP} \delta$ actually attenuates fibrotic responses in the well-established UUO model of renal fibrosis as evident from increased TGF- $\beta$ levels and collagen type I synthesis in $\mathrm{C} / \mathrm{EBP} \delta$-deficient obstructed kidneys compared with wild-type obstructed kidneys.

To elucidate the underlying mechanism by which C/EBP $\delta$ would limit UUO-induced fibrosis, we initially focused on the proliferation/apoptosis balance. A distortion in this balance is suggested to contribute to UUO-induced fibrosis, whereas $\operatorname{C/EBP} \delta$ is particularly well known to regulate the proliferation/apoptosis balance. In the current study, we did not observe major differences in either proliferation or apoptosis in obstructed wild-type $v s \mathrm{C} / \mathrm{EBP} \delta$-deficient kidneys. This result may be surprising in light of the role of C/EBP $\delta$ in proliferation/apoptosis, although one should realize that most of the studies implying $\mathrm{C} / \mathrm{EBP} \delta$ in proliferation/apoptosis have been performed in cancer cells. Indeed, $\mathrm{C} / \mathrm{EBP} \delta$ induces growth arrest and apoptosis in different cancer cell lines, ${ }^{16,22}$ whereas $\mathrm{C} / \mathrm{EBP} \delta$ silencing by promoter hypermethylation is positively correlated with tumor progression. ${ }^{38,39}$ Importantly, however, C/EBP $\delta$ also drives pro-apoptotic gene expression during mammary gland involution, ${ }^{19,20}$ and $\mathrm{C} / \mathrm{EBP} \delta$ is thus not only involved in proliferation/apoptosis in a cancer setting. Most likely, $\mathrm{C} / \mathrm{EBP} \delta$ exerts its effect on proliferation/apoptosis in a cell type dependent manner, and $\mathrm{C} / \mathrm{EBP} \delta$ may not be considered a general driver of apoptosis.

Accumulating evidence suggest that $\mathrm{C} / \mathrm{EBP} \delta$ might have an important role in macrophage function, and we recently showed that migration of macrophages upon Klebsiellainduced pneumonia was significantly decreased in $\operatorname{C/EBP} \delta$ deficient mice. ${ }^{24}$ In the current study, we did, however, not observe any difference in macrophage numbers in obstructed kidneys of wild-type and C/EBP $\delta$-deficient mice. Consequently, $\mathrm{C} / \mathrm{EBP} \delta$ does not limit renal fibrosis during obstructive nephropathy by modifying macrophage recruitment. Alternatively, $\mathrm{C} / \mathrm{EBP} \delta$ could modify macrophage function during UUO. However, macrophage-dependent TGF- $\beta$ production, a key process in UUO-induced fibrosis, is not affected by $\mathrm{C} / \mathrm{EBP} \delta$ in vitro. Indeed, TGF- $\beta$ production is similar in wild-type and $\mathrm{C} / \mathrm{EBP} \delta$-deficient bone marrowderived macrophages and/or tubular epithelial cells (unpublished data). Overall, $\mathrm{C} / \mathrm{EBP} \delta$-driven processes in macrophages do not seem to explain the observed difference in UUO-induced fibrosis.

As already touched upon, another hallmark of the development of renal fibrosis is microvasculature injury, ${ }^{40}$ and disruption of the endothelial integrity may potentiate fibrosis after obstruction of the ureter. ${ }^{6,7}$ Interestingly, C/EBP $\delta$ limits UUO-induced vascular leakage as evident from a significant increase in edema in obstructed kidneys from $\mathrm{C} / \mathrm{EBP} \delta$ deficient mice as compared with wild-type mice. It is tempting to speculate that $\mathrm{C} / \mathrm{EBP} \delta$-dependent prevention of vascular barrier disruption indeed limits subsequent interstitial fibrosis, but ongoing studies are needed to prove or refute this hypothesis.

It is well established that $\alpha \mathrm{SMA}$ levels are increased during UUO. Indeed, we also observed increased levels of $\alpha \mathrm{SMA}$ both on the mRNA and protein level, but the increase was similar in wild-type and $\mathrm{C} / \mathrm{EBP} \delta$-deficient obstructed kidneys (Supplementary Figure 1). This is in contrast to recent data that $\alpha \mathrm{SMA}$ is regulated by $\mathrm{C} / \mathrm{EBP} \delta$ in $\mathrm{Habu}$-venom-induced glomerulonephritis. ${ }^{29}$ More importantly, the authors also state, but do not show, that $\alpha$ SMA mRNA levels are reduced in $\mathrm{C} / \mathrm{EBP} \delta$-deficient mice during UUO. At this moment, we do not have a proper explanation for these seemingly contradictory results, although it is difficult to compare our data with these unpublished observations, as no experimental details are available.

Overall, we show that $\mathrm{C} / \mathrm{EBP} \delta$ limits UUO-induced renal fibrosis by a mechanism not related to the proliferation/ apoptosis balance or infiltration of macrophages. Irrespective of the actual mechanism, however, we pinpoint $\mathrm{C} / \mathrm{EBP} \delta$ as a key factor in the prevention of renal interstitial fibrosis.

Supplementary Information accompanies the paper on the Laboratory
Investigation website (http://www.laboratoryinvestigation.org)

\section{ACKNOWLEDGMENTS}

This study was supported by grant C06.2198 from the Dutch Kidney foundation to JD. We thank Dr Esta Sterneck for providing the C/EBP $\delta$ deficient mice, and Joost Daalhuisen and Marieke ten Brink for technical assistance with the mouse experiments.

\section{DISCLOSURE/CONFLICT OF INTEREST}

The authors declare no conflict of interest.

1. Wynn TA. Common and unique mechanisms regulate fibrosis in various fibroproliferative diseases. J Clin Invest 2007;117: 524-529.

2. Becker GJ, Hewitson TD. The role of tubulointerstitial injury in chronic renal failure. Curr Opin Nephrol Hypertens 2000;9:133-138. 
3. Liu Y. Cellular and molecular mechanisms of renal fibrosis. Nat Rev Nephrol 2011;7:684-696.

4. Bascands JL, Schanstra JP. Obstructive nephropathy: Insights from genetically engineered animals. Kidney Int 2005;68:925-937.

5. Eddy AA. Molecular basis of renal fibrosis. Pediatr Nephrol 2000;15: 290-301.

6. Ohashi R, Shimizu A, Masuda $Y$, et al. Peritubular capillary regression during the progression of experimental obstructive nephropathy. J Am Soc Nephrol 2002;13:1795-1805.

7. Rouschop KM, Claessen N, Pals ST, et al. CD44 disruption prevents degeneration of the capillary network in obstructive nephropathy via reduction of TGF-beta 1-induced apoptosis. J Am Soc Nephrol 2006; 17:746-753.

8. Iwano M, Neilson EG. Mechanisms of tubulointerstitial fibrosis. Curr Opin Nephrol Hypertens 2004;13:279-284.

9. Klahr S, Morrissey J. Obstructive nephropathy and renal fibrosis. Am J Physiol Renal Physiol 2002;283:F861-F875.

10. Strutz F, Neilson EG. New insights into mechanisms of fibrosis in immune renal injury. Springer Semin Immunopathol 2003;24:459-476.

11. Gobe GC, Axelsen RA. Genesis of renal tubular atrophy in experimental hydronephrosis in the rat-role of apoptosis. Lab Invest 1987;56: 273-281.

12. Klahr S. Obstructive nephropathy. Kidney Int 1998;54:286-300.

13. Lopez-Hernandez FJ, Lopez-Novoa JM. Role of TGF-beta in chronic kidney disease: an integration of tubular, glomerular and vascular effects. Cell Tissue Res 2012;347:141-154.

14. Zeisberg M, Neilson EG. Mechanisms of tubulointerstitial fibrosis. J Am Soc Nephrol 2010;21:1819-1834.

15. Lekstrom-Himes J, Xanthopoulos KG. Biological role of the CCAAT/ enhancer-binding protein family of transcription factors. J Biol Chem 1998;273:28545-28548.

16. Gery S, Tanosaki S, Hofmann WK, et al. C/EBPdelta expression in a BCRABL-positive cell line induces growth arrest and myeloid differentiation. Oncogene 2005;24:1589-1597.

17. Ikezoe T, Gery S, Yin D, et al. CCAAT/enhancer-binding protein delta: a molecular target of 1,25-dihydroxyvitamin D3 in androgen-responsive prostate cancer LNCaP cells. Cancer Res 2005;65:4762-4768.

18. Pawar SA, Sarkar TR, Balamurugan K, et al. C/EBP beta targets cyclin D1 for proteasome-mediated degradation via induction of CDC27/APC3 expression. Proc Natl Acad Sci USA 2010;107:9210-9215.

19. Stein T, Salomonis N, Nuyten DS, et al. A mouse mammary gland involution mrna signature identifies biological pathways potentially associated with breast cancer metastasis. J Mammary Gland Bio Neoplasia 2009;14:99-116.

20. Thangaraju $M$, Rudelius $M$, Bierie $B$, et al. C/EBPdelta is a crucial regulator of pro-apoptotic gene expression during mammary gland involution. Development 2005;132:4675-4685.

21. O'Rourke J, Yuan R, DeWille J. CCAAT/enhancer-binding protein-delta C/EBP-delta is induced in growth-arrested mouse mammary epithelial cells. J Biol Chem 1997;272:6291-6296.

22. Sivko GS, DeWille JW. CCAAT/enhancer binding protein delta C/EBP delta regulation and expression in human mammary epithelial cells: I. 'Loss of function' alterations in the C/EBP delta growth inhibitory pathway in breast cancer cell lines. J Cell Biochem 2004;93:830-843.

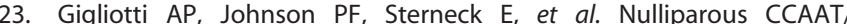
enhancer binding protein delta C/EBP delta knockout mice exhibit mammary gland ductal hyperlasia. Exp Biol Med Maywood 2003; 228:278-285.

24. Duitman J, Hoogendijk AJ, Groot AP, et al. CCAAT-enhancer binding protein delta C/EBPdelta protects against Klebsiella pneumoniaeinduced pulmonary infection: potential role for macrophage migration. J Infect Dis 2012;206:1826-1835.

25. Chang LH, Huang HS, Wu PT, et al. Role of macrophage CCAAT/ enhancer binding protein delta in the pathogenesis of rheumatoid arthritis in collagen-induced arthritic mice. Plos ONE 2012;7:e45378.

26. Ko CY, Chang LH, Lee YC, et al. CCAAT/enhancer binding protein delta CEBPD elevating PTX3 expression inhibits macrophage-mediated phagocytosis of dying neuron cells. Neurobiol Aging 2012;33:e11-e25.

27. Yan $\mathrm{C}$, Johnson PF, Tang $\mathrm{H}$, et al. CCAAT/enhancer-binding protein delta is a critical mediator of lipopolysaccharide-induced acute lung injury. Am J Pathol 2012;182:420-430.

28. Balamurugan K, Sharan S, Klarmann KD, et al. FBXW7alpha attenuates inflammatory signalling by downregulating C/EBPdelta and its target gene Tlr4. Nat Commun 2013;4:1662.

29. Takeji M, Kawada N, Moriyama T, et al. CCAAT/Enhancer-binding protein delta contributes to myofibroblast transdifferentiation and renal disease progression. J Am Soc Nephrol 2004;15:2383-2390.

30. Sterneck E, Paylor R, Jackson-Lewis V, et al. Selectively enhanced contextual fear conditioning in mice lacking the transcriptional regulator CCAAT/enhancer binding protein delta. Proc Natl Acad Sci USA 1998;95:10908-10913.

31. Rouschop KMA, Sewnath ME, Claessen N, et al. CD44 deficiency increases tubular damage but reduces renal fibrosis in obstructive nephropathy. J Am Soc Nephrol 2004;15:674-686.

32. Vilaysane $A$, Chun J, Seamone $M E$, et al. The NLRP3 inflammasome promotes renal inflammation and contributes to CKD. J Am Soc Nephrol 2010;21:1732-1744.

33. Duitman J, Schouten M, Groot AP, et al. CCAAT/enhancer-binding protein delta facilitates bacterial dissemination during pneumococcal pneumonia in a platelet-activating factor receptor-dependent manner. Proc Natl Acad Sci USA 2012;109:9113-9118.

34. Pulskens WP, Rampanelli E, Teske GJ, et al. TLR4 promotes fibrosis but attenuates tubular damage in progressive renal injury. J Am Soc Nephrol 2010;21:1299-1308.

35. Bijlsma MF, Leenders PJ, Janssen BJ, et al. Endogenous hedgehog expression contributes to myocardial ischemia-reperfusion-induced injury. Exp Biol Med Maywood 2008;233:989-996.

36. Farris $A B$, Colvin RB. Renal interstitial fibrosis: mechanisms and evaluation. Curr Opin Nephrol Hypertens 2012;21:289-300.

37. Grgic I, Campanholle G, Bijol V, et al. Targeted proximal tubule injury triggers interstitial fibrosis and glomerulosclerosis. Kidney Int 2012;82: 172-183.

38. Agrawal S, Hofmann WK, Tidow N, et al. The C/EBP delta tumor suppressor is silenced by hypermethylation in acute myeloid leukemia. Blood 2007;109:3895-3905.

39. Tang D, Sivko GS, DeWille JW. Promoter methylation reduces C/EBP delta CEBPD gene expression in the SUM-52PE human breast cancer cell line and in primary breast tumors. Breast Cancer Res Treat 2006;95: 161-170.

40. Kim W, Moon SO, Lee SY, et al. COMP-angiopoietin-1 ameliorates renal fibrosis in a unilateral ureteral obstruction model. J Am Soc Nephrol 2006;17:2474-2483. 